\title{
Sequence of an avian adenovirus (CELO) DNA fragment $(0-11.2 \%)$
}

T.A.Akopian, V.A.Kruglyak, M.B.Rivkina, B.S.Naroditsky and T.I.Tikhonenko Institute of Agricultural Biotechnology All-Union Academy of Agricultural Sciences, Building 4, 12 Pskovskaya Street, Moscow 127253, USSR

The nucleotide sequence of a DNA fragment $(0-11.2 \%)$ from avian adenovirus serotype FAV-1 (CELO; chicken embryo lethal orphan virus, strain Phelps) genome has been determined. The leftmost 63 nucleotides of the sequence represent an inverted terminal repeat which coincides with the repeat sequence published previously [1]. A region of the sequence positioned at 3777 to 4216 including the VA-RNA gene is exactly identical to the CELO DNA sequence reported in [2]. Open reading frames of E1A and E1B transforming regions characteristic of analogous (left terminal $0-11 \%$ ) fragments in mammalian adenovirus genomes were not identified in the CELO genome fragment sequenced, at least in the same polarity. According to our data the $0-11.2 \%$ fragment fails to transform primary cells unlike the $0-18 \%$ fragment which has transforming activity. Thus the location of the transforming region in CELO DNA may be shifted rightwards from the genome leftmost part.

\section{REFERENCES}

1. Aleström,P., Stenlund,A., Li,P. and Pettersson,U. (1982) Gene 18, 193-197. 2. Larsson,S., Bellet,A. and Akusjarvi,G. (1986) J. Virol. 58, 600.

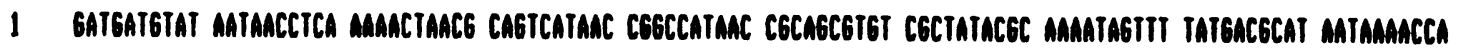

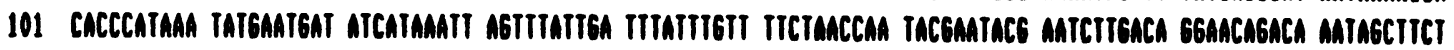

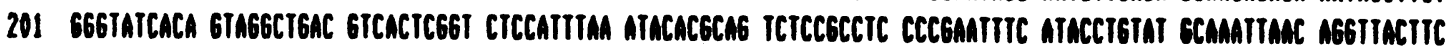

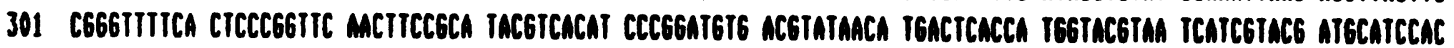

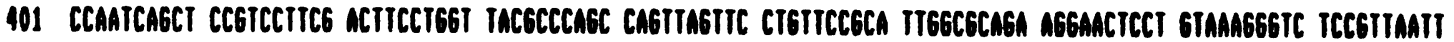

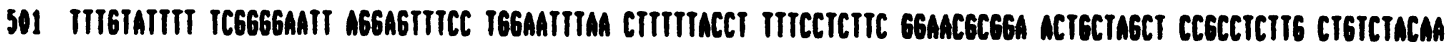

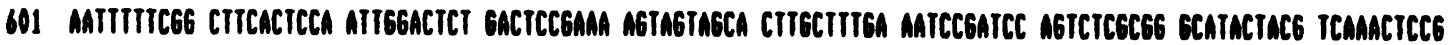

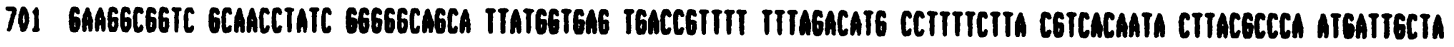

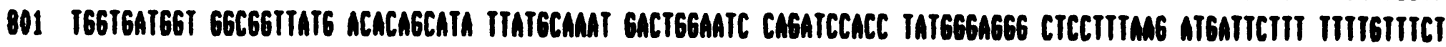

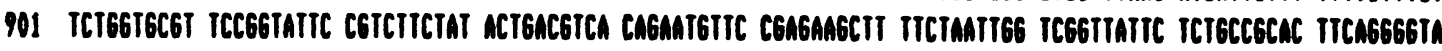

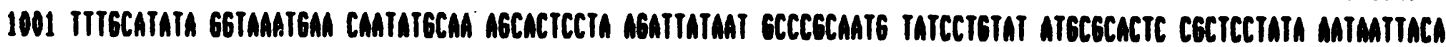

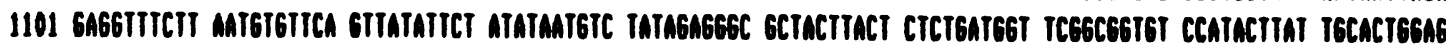

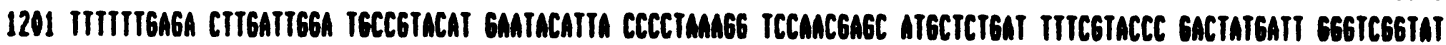

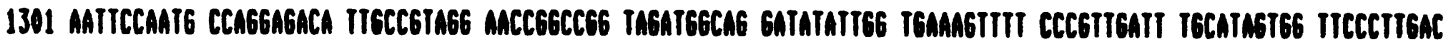

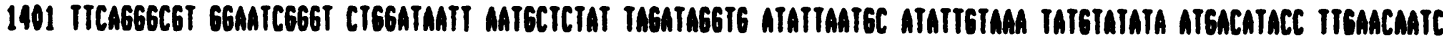

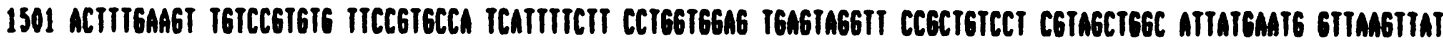

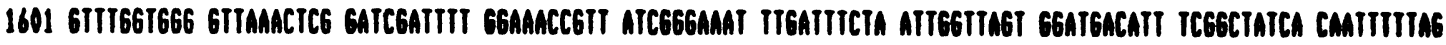

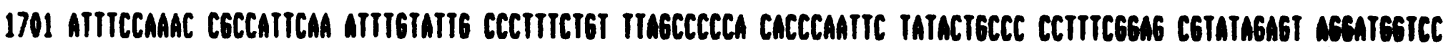

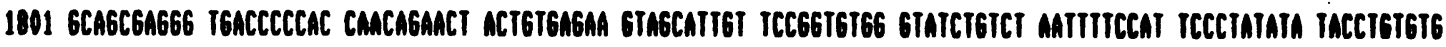

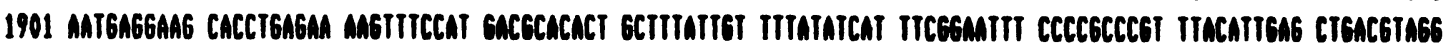

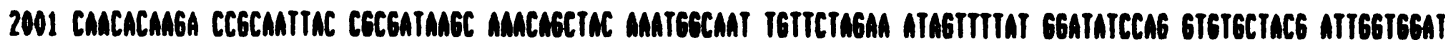

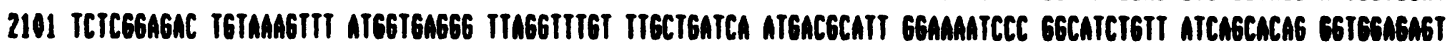

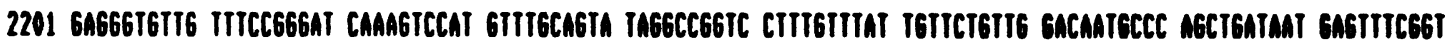

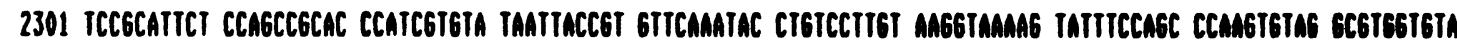

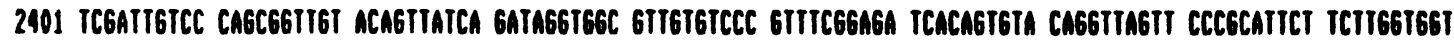

